\title{
TINGKAT KEPATUHAN PERAWAT DALAM IMPLEMENTASIFIVE MOMENTS CUCI TANGAN DI RSUD YOWARI KABUPATEN JAYAPURA
}

\author{
Risma Pangaribuan ${ }^{1}$, Viertianingsih Patungo $^{2}$, Sudarman $^{3}$ \\ ${ }^{1)}$ Rumah Sakit Umum Dareah Kabupaten Jayapura \\ ${ }^{23)}$ Prodi Keperawatan STIKES Jayapura \\ email: patungoviertianingsih@gmail.com
}

\begin{abstract}
ABSTRAK
Five moments for hand hygiene atau five moments cuci tangan merupakan salah satu upaya pencegahan penularan infeksi dari setiap tindakan yang dilakukan oleh petugas kesehatan. Angka kejadian infeksi di rumah sakit (infeksi nosokomial) ini disebabkan adanya faktor endogen (umur, jenis kelamin, penyakit penyerta, daya tahan tubuh, kondisi-kondisi lokal) atau faktor eksogen (lama penderita dirawat, kelompok yang merawat, alat medis, lingkungan). Tujuan penelitian untuk mengetahui tingkat kepatuhan perawat dalam implementasi five moments cuci tangan di RSUD Yowari Kabupaten Jayapura. Metode enelitian yaitu penelitian deskriptif kuantitatif dengan menggunakan metode pendekatan non-participant observation. Kuesioner menggunakan lembar observasi five moments for hand hygiene dari WHO. Jumlah sampel 30 orang. Penelitian ini dilakukan di Ruang Rawat Bedah dan Ruang ICU, pada bulan November 2019. Hasil penelitian menunjukkan tingkat kepatuhan perawat dalam implementasi five moments cuci tangan pada kategori patuh 5 orang $(16.7 \%)$ dan tidak patuh 25 orang $(83.3 \%)$. Selain itu juga peneliti menemukan bahwa implementasi five moments cuci tangan masih rendah terutama pada moments pertama (sebelum kontak dengan pasien), kedua (sebelum melakukan prosedur aseptik), dan kelima (setelah menyentuh peralatan disekitar lingkungan). Kesimpulan penelitian yaitun tingkat kepatuhan perawat sebagian besar berada pada kategori tidak patuh, sehingga masih perlunya peningkatan pengetahuan dan kebiasaan five moments cuci tangan pada setiap perawat. Rumah sakit juga dapat memicu peningkatan kebiasaan ini dengan menggunakan sistem reward sebagai daya tarik bagi para perawat dalam menjalankan kepatuhan dalam melakukan five moments cuci tangan.
\end{abstract}

Kata Kunci: Kepatuhan, Perawat, Five Moments Cuci Tangan

\begin{abstract}
Five moments hand hygiene is one of the efforts to prevent transmission of infection from every action taken by a health worker. The incidence of infection in a hospital (nosocomial infection) is caused by endogenous factors (age, sex, disease concomitant, immune system, local conditions) or exogenous factors (length of time the patient is treated, the group that treats, medical devices, the environment). Research objectives to determine the level of compliance of nurses in the implementation of five moments of hand washing in Yowari District Hospital, Jayapura Regency. the methods is quantitative descriptive research using the Non Participant Observation approach. The questionnaire uses from WHO for five moments hand hygiene observation sheet. The number of samples is 30 nurses. This research was conducted in the Operating Room and ICU Room, in November 2019. The result was found that the level of nurses compliance in the implementation of five moments of hand washing in the category of obedient 5 people (16.7\%) and 25 noncompliant people (83.3\%). In addition, researchers also found that the implementation of five moments hand washing was still low, especially in the first moments (before contact with patients), the second (before carrying out aseptic procedures), and the fifth (after touching equipment around the environment). The conclusion is still a need to increase the knowledge and habits of the five moments of hand washing for each nurse. Hospitals can also trigger an increase in this habit by using a reward system as an attraction for nurses in carrying out the habit of continuing to do five moments of hand washing.
\end{abstract}

Keywords: Compliance, Five Moments Hand Hygiene, Nurses 


\section{PENDAHULUAN}

Five moments for hand hygiene atau five moments cuci tangan merupakan salah satu upaya pencegahan penularan infeksi dari setiap tindakan yang dilakukan oleh petugas kesehatan baik itu sebelum bersentuhan dengan pasien, sebelum melakukan prosedur bersih/ steril, setelah bersentuhan dengan cairan tubuh pasien resiko tinggi, setelah bersentuhan dengan pasien, dan setelah bersentuhan dengan lingkungan sekitar pasien (WHO, 2009).

HAIs (Health Care Associated Infection) merupakan infeksi yang terjadi selama menjalani perawatan di rumah sakit di United Kingdom (UK) menunjukan sekitar 722.000 pasien terkena HAIs, dan sekitar 75.000 orang diantaranya meninggal dikarenakan infeksi tersebut (CDC, 2016). Menurut World Health Organization (WHO, 2016) angka kejadian HAIs terjadi pada $15 \%$ semua pasien rawat inap dengan tingkat kejadian sekitar $75 \%$ di negara-negara Asia Tenggara dan Subsahara Afrika.

Menurut Departemen Kesehatan (Depkes, 2011) di Indonesia HAIs mencapai $15,74 \%$ jauh diatas negara maju yang berkisar 4,8-15,5\%, sedangkan angka kejadian infeksi di rumah sakit (infeksi nosokomial) sekitar 3-21\% (rata-rata 9\%) atau lebih 1,4 juta pasien rawat inap di rumah sakit seluruh dunia, baik itu disebabkan adanya faktor endogen (umur, jenis kelamin, penyakit penyerta, daya tahan tubuh, kondisi-kondisi lokal) atau faktor eksogen (lama penderita dirawat, kelompok yang merawat, alat medis, lingkungan).

Tingginya angka prevalensi kejadian HAIs merupakan ancaman bagi pelayanan rumah sakit. Oleh sebab itu, di rumah sakit terdapat kegiatan pencegahan dan pengendalian infeksi (PPI) difasilitas pelayanan kesehatan yang merupakan suatu standar mutu pelayanan dan penting bagi pasien, petugas kesehatan maupun pengunjung. Pengendalian infeksi harus dilaksanakan oleh seluruh fasilitas pelayanan kesehatan untuk melindungi pasien, petugas kesehatan dan pengunjung (Kemenkes, 2017).

Akibat banyaknya kerugian yang disebabkan oleh HAIs memerlukan upaya untuk menekan angka kejadian tersebut, salah satunya dengan membersihkan tangan, karena 80\% infeksi disebarkan melalui tangan (Keevil, 2011). Beberapa patogen penyebab HAIs memiliki frekuensi yang cukup tinggi di tangan, seperti: staphlococcus aureus yang merupakan penyebab utama dari infeksi luka paska operasi, pneumonia memiliki frekuensi sekitar 10-78\% di tangan, pseudomonas merupakan patogen penyebab infeksi nafas bawah memiliki frekuensi sekitar 1-25\% di tangan, dan jamur termasuk candida sekitar 23$81 \%$ serta dapat bertahan selama satu jam di tangan (Listiowati \& Nilamsari, 2015).

Petugas kesehatan memiliki resiko tinggi menularkan patogen melalui tangan, sebuah penelitian pada 40 rumah sakit melaporkan kepatuhan tenaga kesehatan yang melakukan hand hygiene sebelum dan setelah kepasien bervariasi antara 24\% sampai $89 \%$ (rata-rata 56,6 \%) (Suryoputri, 2011). Sasaran evaluasi pelaksanaan hand hygiene di rumah sakit dapat terdiri dari: perawat, asisten perawat, orderlies, dokter, residen, farmasi, dan therapist, ahli teknisi dan teknologi, staf non klinis (asisten administrasi, staf kantor), staf lingkungan (IPSRS, IPAL, petugas kebersihan, petugas keamanan), pekerja sosial rumah sakit, staf penyaji makanan, sopir, vendor, mahasiswa, pengunjung, dan penunggu pasien (WHO, 2009).

Perawat merupakan salah satu tenaga kesehatan oleh karena itu perawat memiliki peluang yang besar dalam implementasi five moments cuci tangan, dari penelitian Pateda \& Rabbani (2013) diketahui bahwa pengetahuan perawat tentang five moment cuci tangan masih dalam kategori kurang baik yaitu sebesr $70,5 \%$. Wilayah Papua sendiri belum ada data atau penelitian mengenai five moments cuci tangan oleh sebab itu peneliti berusaha untuk menggambarkan five moments cuci tangan di RSUD Yowari.

Pengambilan data awal yang dilakukan di RSUD Yowari bagian komite PPI bulan September 2019 diketahui bahwa nilai indikator pencaipaian kepatuhan five moments cuci tangan masih di bawah $30 \%$ dari $100 \%$ hal tersebut dikarenakan banyak perawat yang masih kurang menyadari keharusan dalam mencuci tangan terlebih dahulu sebelum kontak dengan pasien serta banyak perawat yang tidak melakukan cuci tangan setelah kontak dengan pasien terlebih jika perawat tersebut hanya beberapa detik kontak dengan pasien.

Dari hasil wawancara yang dilakukan peneliti dengan Kepala Ruangan Bedah dan ICU, mengemukakan bahwa penerapan cuci tangan baru digencarkan pada awal bulan Januari 2018, tetapi belum terlalu terlihat implementasinya di dalam ruangan. Selain itu, Kepala Bidang Keperawatan RSUD Yowari juga mengatakan bahwa PPI sudah sering melakukan sosialisasi mengenai cuci tangan 
namun masih banyak perawat yang belum patuh dalam melakukan cuci tangan terlebih dalam menerapkan five moment cuci tangan.

Berdasarkan uraian tersebut peneliti tertarik untuk melakukan penelitian tentang tingkat kepatuhan perawat dalam implementasi five moments cuci tangan di RSUD Yowari Kabupaten Jayapura.

\section{METODE PENELITIAN}

Jenis penelitian ini menggunakan deskriptif kuantitatif dengan metode pendekatan NonParticipant Observation. Penelitian ini dilaksanakan pada bulan September - November 2019. Pengambilan sampel dalam penelitian ini menggunakan teknik total sampling yaitu mengambil keseluruhan jumlah dari populasi untuk dijadikan objek penelitian yang berjumlah 30 responden sesuai kriteria inklusi dan eksklusi.

Terdapat 2 instrumen yang digunakan dalam penelitian diantaranya: kuesioner karakteristik responden, dan kuesioner kepatuhan implementasi five moments cuci tangan yang dijabarkan dari WHO dan analisa data penelitian ini menggunakan univariat yang disajikan dalam bentuk tabel persentase.

\section{HASIL PENELITIAN}

Analisa univariat dalam penelitian ini memaparkan mengenai karakteristik responden (umur, jenis kelamin, pendidikan terakhir, ruang kerja, lama kerja, pelatihan dan waktu pelatihan PPI) dan tingkat kepatuhan implementasi five moments cuci tangan.

Tabel 1 Karakteristik Responden

\begin{tabular}{lcc}
\hline Karakteristik & Frekuensi & $\mathbf{( \% )}$ \\
\hline Umur & & \\
26-35 tahun & 23 & 76.7 \\
36-45 tahun & 7 & 23.3 \\
Total & 30 & 100.0 \\
\hline Jenis Kelamin & & \\
Laki-laki & 4 & 13.3 \\
Perempuan & 26 & 86.7 \\
Total & 30 & 100 \\
\hline Pendidikan & & \\
SPK & 2 & 6.7 \\
D3 & 24 & 80.0 \\
Ners & 3 & 10.0 \\
S2 & 1 & 3.3 \\
Total & 30 & 100.0 \\
\hline Ruangan & & \\
Bedah & 15 & 50.0 \\
ICU & 15 & 50.0 \\
\hline
\end{tabular}

\begin{tabular}{lcc}
\hline Total & 30 & 100.0 \\
\hline Lama Kerja & & \\
$\quad<5$ Tahun & 10 & 33.3 \\
$\quad>5$ Tahun & 20 & 66.7 \\
Total & 20 & 100.0 \\
\hline Pelatihan PPI & & \\
$\quad$ Pernah & 4 & 13.3 \\
$\quad$ Tidak Pernah & 26 & 86.7 \\
Total & 30 & 100.0 \\
\hline Waktu Pelatihan PPI & & \\
$\quad$ Tidak Pernah & 26 & 86.7 \\
1 Kali & 3 & 10.0 \\
2 Kali atau lebih & 1 & 3.3 \\
Total & 30 & 100.0 \\
\hline
\end{tabular}

Berdasarkan tabel di atas peneliti menjabarkan umur responden menurut Departemen Kesehatan tahun 2009. Dari 30 respoden yang diteliti, 23 orang atau $76.7 \%$ berumur $26-35$ tahun dan 7 orang atau $23.3 \%$ berumur $36-45$ tahun. Hal ini menunjukkan bahwa sebagian besar responden berumur antara 26-35 tahun, dan paling sedikit berada pada umur 36-45 tahun.

Kriteria responden berdasarkan jenis kelamin. Dari 30 responden yang diteliti, 4 orang atau $13.3 \%$ berjenis kelamin laki-laki dan 26 orang atau $86.7 \%$ berjenis kelamin perempuan. Hal ini menunjukkan bahwa sebagian besar responden berjenis kelamin perempuan dan sangat kecil responden berjenis kelamin laki-laki.

Kriteria responden berdasarkan tingkat pendidikan. Dari 30 responden yang diteliti, 2 orang atau $6.7 \%$ berpendidikan SPK, 24 orang atau $80.0 \%$ berpendidikan D3, 3 orang atau $10.0 \%$ berpendidikan Ners dan 1 orang atau $3.3 \%$ berpendidikan $\mathrm{S} 2$. Hal ini menunjukkan bahwa sebagian besar responden berpendidikan D3 dan sangat kecil responden berpendidikan S2.

Pada tabel 1 peneliti menjabarkan karakteristik responden berdasarkan ruang kerja perawat, dari 30 responden yang diteliti terdapat 15 orang atau $50.0 \%$ bekerja di ruang bedah dan 15 orang atau $50.0 \%$ bekerja di ruang ICU. Hal ini menunjukkan bahwa sama rata antara jumlah perawat yang bekerja di ruang bedah dan ruang ICU, ini terjadi dikarenakan peneliti sengaja mengambil seimbang antara dua ruangan tersebut.

Pada tabel 1 peneliti menjabarkan tentang karakteristik responden berdasarkan lama kerja, dari 30 responden yang diteliti terdapat 10 orang atau $33.3 \%$ telah bekerja kurang dari 5 tahun dan 20 orang atau $66.7 \%$ telah bekerja selama lebih dari 5 tahun. Hal ini menunjukkan bahwa sebagian 
besar perawat telah lama bekerja di Rumah Sakit lebih dari 5 tahun.

Kriteria responden berdasarkan pelatihan PPI yang pernah diikuti. Dari 30 responden yang diteliti, 4 orang atau $13.3 \%$ pernah mengikuti pelatihan PPI dan 26 orang atau $86.7 \%$ belum pernah mengikuti pelatihan PPI. Hal ini menunjukkan bahwa sebagian besar responden belum pernah mengikuti pelatihan PPI dalam melakukan five moments.

Sedangkan, kriteria responden berdasarkan waktu mengikuti pelatihan PPI. Dari 30 responden yang diteliti, 26 orang atau $86.7 \%$ belum pernah mengikuti pelatihan PPI, 3 orang atau $10.0 \%$ pernah 1 kali mengikuti pelatihan PPI dan 1 orang atau $3.3 \%$ pernah 2 kali mengikuti pelatihan PPI.

Tabel 2 tingkat kepatuhan implementasi five moments cuci tangan

\begin{tabular}{cccc}
\hline Karakteristik & & Frekuensi & \\
\cline { 1 - 1 } Tingkat Kepatuhan & & 5 & 16.7 \\
Patuh & & 25 & 83.3 \\
Tidak Patuh & & $\underline{30}$ & $\underline{100.0}$ \\
Total & &
\end{tabular}

Pada tabel 2 peneliti menggambarkan tingkat kepatuhan perawat dalam implementasi five moments cuci tangan. Diketahui dari 30 responden yang diteliti 5 orang atau $16.7 \%$ patuh dalam implementasi five moments cuci tangan dan 25 orang atau $83.3 \%$ tidak patuh dalam implementasi five moments cuci tangan. Hal ini menunjukkan bahwa hampir seluruh responden tidak patuh dalam menjalankan five moments cuci tangan.

\section{PEMBAHASAN}

\section{Karakteristik Responden}

a. Berdasarkan Umur

Dari hasil penelitian yang dilakukan pada tabel 1 sebagian besar responden berada pada rentang umur 26-35 tahun yaitu sebanyak 23 orang $(76.7 \%)$. Hal ini sesuai dengan batasan umur dari Departemen Kesehatan RI (2009) yang menyatakan bahwa umur 26-35 tahun dikategorikan sebagai dewasa awal. Menurut Hurlock (2012) dewasa awal memiliki tugas perkembangan seperti: telah memiliki pekerjaan/ bekerja, mampu menerima tanggung jawab dan mampu mengambil keputusan.
Mathuridy (2015) menyatakan bahwa umur perawat berhubungan dengan banyaknya pengalaman yang diperoleh dalam hidup. Umur juga berkaitan dengan kemampuan fisik dalam melaksanakan tugas dan kewajibannya sebagai perawat, sehingga semakin matang usia seseorang maka semakin dapat menentukan hal-hal yang dianggap baik dan tidak baik, meningkatkan keterampilan serta pengetahuan perawat tentang cuci tangan.

b. Berdasarkan Jenis Kelamin

Hasil penelitian berdasarkan jenis kelamin, sebagian besar responden yaitu 26 orang $(86.7 \%)$ berjenis kelamin perempuan. Hal ini terjadi karena rasio perawat wanita di RS Yowari lebih banyak perempuan daripada laki-laki. Selain itu, menurut Sukron \& Kariasa (2013) perawat perempuan lebih berhatihati dalam menjaga dan melakukan perawatan terhadap pasien sehingga mampu meminimalkan pajanan dari pasien daripada laki-laki.

Pada dasarnya karakteristik perempuan dan laki-laki memang berbeda, bukan hanya dari segi fisik saja, tetapi juga dalam hal bertindak dan berpikir. Perempuan juga cenderung lebih mampu menjadi pendengar yang baik, langsung menangkap fokus diskusi dan tidak selalu berfokus terhadap diri sendiri, sementara laki-laki tidak demikian (Hartono, 2015).

c. Berdasarkan Pendidikan

Berdasarkan tingkat pendidikan, responden terbanyak memiliki status pendidikan D3 yaitu sebanyak 24 orang (80.0\%). Menurut Notoatmodjo (2010) pendidikan dapat memperluas wawasan atau pengetahuan seseorang dan merupakan proses belajar, dimana seseorang yang berpendidikan lebih tinggi akan mempunyai pengetahuan yang lebih luas tentang hand hygiene dibandingkan dengan seseorang yang tingkat pendidikan lebih rendah. Semakin tinggi pendidikan seseorang semakin banyak informasi tentang hand hygiene dan semakin peduli dalam melakukan hand hygiene pada setiap pemberian asuhan keperawatan. 
Faktor pendidikan juga mempengaruhi perilaku seseorang dimana menurut penelitian dari Puspasari (2015) perawat dengan tingkat pendidikan D3, selama proses pendidikannya lebih banyak mendapatkan materi dan pengalaman praktek di rumah sakit apabila dibandingkan dengan perawat pada tingkat pendidikan S1 atau SPK. Selain itu, perawat D3 lebih banyak melakukan tindakan keperawatan sehingga perawat D3 lebih sering untuk berinteraksi dengan pasien, yang mana ketika melakukan interaksi dengan pasien, seorang perawat diharuskan selalu melakukan upaya perlindungan diri, yaitu dengan cara melaksanakan praktik dalam pencegahan infeksi nosokomial.

d. Berdasarkan Ruangan

Dari hasil penelitian terdapat jumlah responden yang sama besar berada di ruang bedan dan ICU yaitu sebanyak 15 orang $(50.0 \%)$. Jumlah responden yang sama rata ini dilakukan oleh peneliti agar mendapatkan jumlah responden yang seimbang pada dua ruangan berbeda.

Sedikit berbeda dengan penelitian yang dilakukan oleh Wulandari \& Sholikah (2017) yang mengambil sampel dari ruang ICU dan NICU RSUD Sukoharjo, dimana mereka menggunakan sampel sebanyak 29 responden dan tidak dijabarkan dengan rinci jumlah per ruangan tersebut.

e. Berdasarkan Lama Kerja

Dari hasil penelitian pada tabel 1 peneliti menjabarkan tentang karakteristik responden berdasarkan lama kerja, dari 30 responden yang diteliti sebagian besar perawat telah lama bekerja di rumah sakit lebih dari 5 tahun yaitu sebanyak 20 orang $(66.7 \%)$.

Berdasarkan hasil penelitian Sukron \& Kariasa (2013) diketahui bahwa responden yang lama kerja $<5$ tahun dan kerja >5 tahun sebagian besar kurang patuh dalam pelaksanaan five moment hand hygiene sebanyak $71,2 \%$ dan $69,1 \%$, hal ini mungkin berhubungan dengan pengalaman selama bekerja, dimana pengalaman dapat diperoleh dari pengalaman sendiri maupun orang lain.
Pengalaman yang sudah diperoleh dapat memperluas pengetahuan seseorang dan dapat meningkatkan kedisiplinan dalam melakukan tindakan berdasarkan pengalaman yang sudah dialami.

Menurut Azwar (2009) apa yang telah dialami seseorang akan ikut membentuk dan mempengaruhi penghayatan terhadap stimulasi sosial yang akan menjadi salah satu dasar terbentuknya sikap. Peningkatan pengalaman akan meningkatkan ketrampilan perawat dan diharapkan kepercayaan diri perawat dapat meningkat sehingga memotivasi dan performa kerja yang ditampilkan akan semakin baik.

f. Berdasarkan Pelatihan dan Waktu Pelatihan PPI

Kriteria responden berdasarkan pelatihan PPI yang pernah diikuti. Dari 30 responden yang diteliti, sebagian besar belum pernah mengikuti pelatihan PPI sebanyak 26 orang $(86.7 \%)$ dan 3 orang $(10.0 \%)$ pernah 1 kali mengikuti pelatihan PPI.

Rumah sakit wajib mempunyai SOP sebagai acuan dalam pelaksanaan hand hygiene yang mengacu pada lembaga internasional yaitu WHO. Tim PPI mencari pokok permasalahan dalam hand hygiene apabila perawat tidak melakukan hand hygiene maka akan mendapatkan teguran, SOP untuk melakukan hand hygiene biasanya dilakukan saat meeting morning juga diharuskan untuk melakukan setiap tindakan, baik sebelum kontak maupun sesudah kontak (Marfu'ah \& Sofiana, 2018).

2. Analisis Tingkat Kepatuhan Perawat Dalam Implementasi Five Moments Cuci Tangan

Berdasarkan hasil penelitian pada tabel 2 diketahui terdapat 25 orang $(83.3 \%)$ tidak patuh dan 5 orang (16.7\%) patuh dalam implementasi five moments cuci tangan. Kepatuhan adalah tingkat seseorang melaksanakan suatu cara atau berperilaku sesuai dengan apa yang disarankan atau dibebankan kepadanya. Perubahan perilaku individu baru dapat menjadi optimal jika perubahan tersebut terjadi melalui proses internalisasi dimana perilaku yang baru itu 
dianggap bernilai positif bagi diri individu itu sendiri dan diintegrasikan dengan nilai-nilai lain dari hidupnya (Sukron \& Kariasa, 2013).

Berbeda dengan penelitian yang dilakukan oleh Sobur (2015) yang menyatakan kepatuhan baik sebesar 68 perawat $(63,6 \%)$ dan kepatuhan kurang sebanyak 39 perawat (36,6\%), serta penelitian Meisa (2012) menyatakan perilaku perawat yang memiliki kategori baik sebanyak 85 perawat $(69,1 \%)$ dan 38 perawat $(30,9 \%)$ memiliki kategori kurang baik. Hal ini terlihat bahwa seharusnya perawat memiliki kepatuhan yang baik dan diimplementasikan dalam setiap perilaku perawat dalam five moments cuci tangan.

Berdasarkan penelitian yang dilakukan oleh Damanik (2012) tentang kepatuhan hand hygiene di RS Immanuel Bandung didapatkan hasil bahwa terdapat hubungan antara pengetahuan $(\mathrm{p}=0,000)$ dan lama kerja $(\mathrm{p}=0,026)$ dengan kepatuhan hand hygiene cuci tangan. Menurut WHO (2009) hand hygiene idealnya $100 \%$ perawat mampu melakukan five moment cuci tangan yang dilakukan baik berupa hand wash maupun hand rub.

Menurut Sukron \& Kariasa (2013) kepatuhan terbagi menjadi tiga yaitu kepatuhan penuh, kepatuhan sebagian, dan ketidakpatuhan. Kepatuhan penuh merupakan kondisi dimana perawat secara konsisten dan penuh kesadaran melakukan apa yang disarankan, kepatuhan sebagian adalah kondisi dimana perawat terkadang mengikuti saran dan terkadang tidak, dan ketidakpatuhan merupakan kondisi dimana perawat meninggalkan saran dan anjuran.

Dari hasil analisa data juga peneliti menemukan bahwa implementasi five moments cuci tangan masih rendah terutama pada moments pertama (sebelum kontak dengan pasien), kedua (sebelum melakukan prosedur aseptik), dan kelima (setelah menyentuh peralatan disekitar lingkungan).

Kurangnya kesadaran terhadap penularan penyakit dari perawat ke pasien masih rendah dan mobilitas interaksi antara perawat yang cukup tinggi dalam setiap pemberian pelaksanaan asuhan keperawatan membuat perawat menjadi tenaga kesehatan yang paling sering menggunakan sarung tangan, hal ini membuat perawat beranggapan bahwa dirinya sudah terproteksi sehingga perawat mengabaikan prosedur five moments cuci tangan (Andaruni., dkk, 2014).

Asumsi petugas kesehatan dengan memakai sarung tangan maka rantai penyebaran infeksi telah dapat terputus, padahal seharusnya hand hygiene tetap harus dilakukan sebelum memakai sarung tangan karena kuman masih berpotensi keluar dari sarung tangan lewat celah yang terdapat dipergelangan tangan (Nurani \& Hidajah, 2017).

Selain itu, faktor yang mendasari kesadaran perawat adalah pengetahuan, dapat diperoleh melalui pendidikan, sosialisasi maupun pelatihan. Faktor yang mungkin mempengaruhi kepatuhan adalah motivasi yang tinggi. Motivasi yang tinggi dimiliki oleh perawat dapat meningkatkan kepatuhan perawat dalam melaksanakan hand hygiene yang terintegrasi dalam five moments cuci tangan dan enam langkah cuci tangan baik hand wash maupun hand rub (Sani \& Pratiwi, 2017).

Menurut penelitian Sinaga (2015) terdapat faktor pendukung (enabling factor) seperti ketersediaan sarana mencuci tangan yang memadai dapat mempengaruhi kepatuhan perawat dalam melakukan hand hygiene. Menurut Sobur (2015) kampanye poster dan petunjuk five moments cuci tangan harus ditingkatkan disemua ruang perawatan dalam upaya peningkatan kepatuhan cuci tangan. Kepatuhan cuci tangan akan mendukung upaya keselamatan perawat selama bekerja di rumah sakit. Pengamatan kepatuhan mencuci tangan sebaiknya dilakukan secara regular untuk memantau efektifitas usaha-usaha peningkatan kepatuhan cuci tangan.

Hasil penelitian ini juga diketahui bahwa masih kurangnya informasi mengenai five moments cuci tangan yang didapatkan dari bidang PPI. Sesuai dengan hasil penelitian yang dilakukan oleh Sinaga (2015) bahwa ketidakpatuhan perawat dikarenakan perawat belum mendapatkan konsep teori dan cara melakukan pencegahan infeksi nosokomial atau hand hygiene secara benar akibatnya perawat belum melakukan pencegahan infeksi nosokomial atau hand hygiene secara maksimal ketika sudah mulai bekerja. 
Peneliti merasa bahwa terdapat faktor lainnya yang mungkin berkontribusi terhadap kepatuhan yang rendah dalam five moments cuci tangan seperti beban kerja perawat yang tinggi, dimana di ruangan seorang perawat menangani 5-6 orang pasien, padahal idealnya satu perawat menangani 2-3 orang pasien. Beban kerja perawat yang tinggi tentunya mempengaruhi kepatuhan perawat dalam five moments cuci tangan, karena terkadang dengan beban kerja yang tinggi, perawat dapat lupa untuk cuci tangan karena sibuk dengan pemenuhan kebutuhan pasien di ruangan.

Selain itu juga mungkin belum adanya reward yang diberikan perawat dalam hal kepatuhan melakukan tindakan keperawatan secara rutin. Pemberian reward dapat diberikan pada perawat ataupun petugas kesehatan yang memang benar-benar selalu melakukan hand hygiene, dengan pemberian reward mungkin saja dapat meningkatkan kepatuhan perawat dalam five moment hand hygiene.

Alasan lainnya juga peneliti temukan dari wawancara antara peneliti terhadap beberapa orang perawat diruangan, didapatkan data bahwa ada beberapa perawat yang berasumsi bahwa semakin sering cuci tangan, akan menimbulkan iritasi pada kulit tangan, sehingga mereka mengurangi frekuensi untuk cuci tangan.

\section{KESIMPULAN}

Dari hasil penelitian diketahui dari 30 responden tingkat kepatuhan perawat dalam implementasi five moments cuci tangan pada kategori patuh 5 orang (16.7\%) dan tidak patuh 25 orang $(83.3 \%)$.

\section{DAFTAR PUSTAKA}

Andaruni, E., Manik, M. J., \& Natalia, S. (2014). Implementasi five moment for hand hygiene oleh perawat unit perawatan intensif Rumah Sakit X. Jurnal Keperawatan.

CDC (Centers for Disease Control and Prevention). (2016). National and State Healthcare Associated Infections Progress Report. United State.

Damanik, S. M. (2012). Kepatuhan hand hygiene di Rumah Sakit Immanuel Bandung. Students e-Journals Unpad, Vol 1, No 1.
Depkes RI. (2009). Profil Kesehatan Indonesia. Jakarta.

Depkes. (2011). Pedoman Manajerial Pencegahan dan Pengendalian Infeksi di Rumah Sakit dan Fasilitas Pelayanan Kesehatan Lainnya. Jakarta.

Hartono, A. (2015). Gambaran perilaku perawat dalam melaksanakan cuci tangan di Ruang Anggrek dan Wijaya Kusuma RSUD Wates. Jurnal Stikes Jenderal Achmad Yani Yogyakarta.

Hurlock, E. B. (2012). Psikologi Perkembangan, Suatu Pendekatan Sepanjang Rentang Kehidupan. Jakarta: Erlangga.

Keevil, B. (2011). Reducing HAIs in ICUs with copper touch surfaces. University of Southampton.

Kemenkes. (2017). Peraturan Menteri Kesehatan Nomor 27 Tahun 2017 tentang Pedoman Pencegahan Dan Pengendalian Infeksi Di Fasilitas Pelayanan Kesehatan.

Listiowati, E., \& Lisa Nilamsari. (2015). Efektivitas pemberian simulasi hand hygiene terhadap kepatuhan hand hygiene petugas non medis di Rumah Sakit PKU Muhammadiyah Yogyakarta Unit II. Jurnal Medicoeticolegal dan Manajemen Rumah Sakit.

Mathuridy, R. (2015). Hubungan umur, lama kerja, pendidikan dan motivasi dengan kepatuhan perawat melakukan enam langkah lima moment cuci tangan di Ruang ICU RSUD Ulin Banjarmasin. Jurnal Penelitian Sekolah Tinggi Ilmu Kesehatan Muhammadiyah Banjarmasin, Vol 3. No 2.

Meisa, A. (2012). Gambaran perilaku mencuci tangan pada perawat di Rumah Sakit Awal Bros Bekasi. Jurnal Fakultas Kesehatan Masyarakat Universitas Indonesia.

Notoatmodjo, S. (2010). Ilmu perilaku kesehatan. Jakarta: Rineka Cipta.

Nurani, R. R. S., \& Hidajah, A. C. (2017). Description of hand hygiene's compliance on nurse of hemodialysis at Haji Hospital Surabaya. J Berk Epidemiol. 2017 Oct;5(2):240-52.

Pateda, V., dan Rabbani, I. (2013). Hubungan pengetahuan terhadap perilaku cuci tangan petugas kesehatan di bagian ilmu kesehatan anak BLU RSUP Prof Dr RD Kandou Manado. Jurnal Kedokteran Universitas 
Sam Ratulangi Manado. Vol 3.No 5. Oktober 2013.

Puspasari, Y. (2015). Hubungan pengetahuan, sikap dengan praktik perawat dalam pencegahan infeksi nosokomial di Ruang Rawat Inap Rumah Sakit Islam Kendal. Jurnal Fakultas Ilmu Keperawatan dan Kesehatan, Vol. 8, No. 1.

Sani, F. N., \& Pratiwi, M. R. (2017). Hubungan motivasi perawat dengan tingkat kepatuhan melakukan cuci tangan di RSI Klaten. Profesi Prof Islam Media Publ Penelit. 14(2):11-8.

Sinaga, S. E. N. (2015). Kepatuhan hand hygiene di Rumah Sakit Misi Rangkasbitung. Jurnal Sekolah Tinggi Kesehatan Santo Borromeus.

Sobur, S. (2015). Hubungan sikap dan kepatuhan cuci tangan pada perawat rawat inap RSUD Kota Semarang. Jurnal Fakultas Ilmu Keperawatan Kesehatan Universitas Muhammadiyah Semarang.

Sukron., \& Kariasa, I. M. (2013). Tingkat kepatuhan perawat dalam pelaksanaan five moment hand hygiene di Irna C RSUP Fatmawati. Jurnal Ilmu Keperawatan Universitas Indonesia.

Suryoputri, A. D. (2011). Perbedaan angka kepatuhan cuci tangan petugas kesehatan di RSUP dr. Kariadi. Studi di bangsal bedah, anak, interna, dan ICU. Artikel karya tulis ilmiah. Semarang.

WHO (World Health Organization). (2009). A Guide to the Implementation of the WHO Multimodal Hand Hygiene Improvement Strategy. Diakses dari http://www.who.int/en.

WHO (World Health Organization). (2009). World Alliance for Patient Safety Global Patient Safety Challenge: 2005-2006. Switzerland: WHO Document Production Servies.

WHO (World Health Organization). (2016). The Burden of Health Care-Associated Infection Worldwide A Summary. Switzerland.

World Health Organization (WHO). (2009). My 5 Moments For Hand Hygiene,www.who.int, diakses dari: http://www.who.int/infectionprevention/campaigns/cleanhands/ 5moments/en/.

Wulandari, R., \& Sholikah, S. (2017). Pengetahuan dan penerapan five moments cuci tangan perawat di RSUD Sukoharjo. Jurnal Kesehatan STIKES Aisyiyah Surakarta. 